\title{
A ANÁLISE ECONÔMICA DO DIREITO: uma dimensão da crematística no Direito
}

Bruno Bolson Lauda ${ }^{1}$

RESUMO: O presente artigo busca traçar, de forma geral, as características principais da chamada "Escola da Análise Econômica do Direito", de Posner, Coase e Calabresi, e compará-la brevemente e sinteticamente com a crematística em Aristóteles, que é a arte da obtenção de riquezas, no sentido de que, sendo esse o objetivo primordial do aspecto normativo da Análise Econômica do Direito, seria ela uma dimensão da crematística no Direito. Busca concluir que a Análise Econômica do Direito se trata da aplicação de métodos crematísticos ao Direito, tão-somente. Diferencia o ponto de vista normativo do ponto de vista descritivo da Análise Econômica do Direito em relação à teoria de Aristóteles.

PALAVRAS-CHAVE: análise econômica do direito, crematística, utilitarismo, pensamento econômico antigo, pensamento econômico moderno, economicismo

\section{ECONOMIC ANALYSIS OF LAW: a dimension of chrematistics in laws}

ABSTRACT: The present article seeks to trace, in a general way, the main characteristics of the so-called "School of Law and Economics", de Posner, Coase e Calabresi, and compare it briefly and synthetically to the chrematistics in Aristotle, which is called the art of acquiring riches, in the sense that, being it the main objective of the normative dimension of the Economic Analysis of Law, it would be a dimension of chrematistics in laws. It concludes that the economic analysis of law is nothing but the use of the chrematistic method into the Law sphere. Establishes the difference between the normative point of view and the descriptive point of view of the Economic Analysis of Law and Aristotle's economic theory.

KEY-WORDS: economic analysis of law, chrematistics, utilitarianism, ancient economic thought, modern economic though, economicism

\footnotetext{
${ }^{1}$ Aluno do Programa de Pós-Graduação em Direito no nível de Mestrado pela Universidade Federal do Rio Grande do Sul (UFRGS).
} 


\section{INTRODUÇÃO}

O presente trabalho tem por fulcro a realização de uma breve análise comparativa entre a chamada "Escola da Análise Econômica do Direito" e a economia e a crematística como concebidas por Aristóteles. Procuramos precisar, pois, até que ponto as proposições e os instrumentos teórico e analíticos típicos da Escola Análise Econômica do Direito nada mais seriam do que uma manifestação de uma dimensão crematística do Direito.

Entendemos por necessária, pois, a busca de maior interdisciplinariedade no trato das questões jurídicas. As ações dos juízes, advogados e demais operadores do Direito, bem como das próprias partes dentro do processo (e mesmo fora dele) têm reflexos econômicos que não devem ser ignorados. Da mesma forma, uma boa teoria do Direito deve encampar os caracteres econômicos do Direito.

Nesse sentido, é também nosso objetivo o de compreender 0 pensamento econômico aristotélico, contrastando-o com o referido na Análise Econômica do Direito, e ressaltando o que tiverem de comum (se tanto).

O material utilizado foi exclusivamente bibliográfico, tendo em vista ser prescindível qualquer análise factual para os objetivos propostos, que é o de contrapôr dois paradigmas teórico-conceituais. Recusamo-nos a realizar uma análise histórica, também, ainda que possa ser útil e perfeitamente realizável em trabalhos posteriores sobre o mesmo tema, em virtude do caráter exclusivamente teórico do enfoque do presente trabalho.

Isto posto, tem-se que o estudo da economia em Aristóteles, para o Direito, se faz importante por duas razões. A primeira, por ser ele, possivelmente, o primeiro pensador a desenvolver uma teoria econômica ${ }^{2}$, e o mais importante da antiguidade. Em dois de seus trabalhos realiza, Aristóteles,

2 YOUNKINS, Edward W. Aristotle and economics. Disponível em: http://www.quebecoislibre.org/05/050915-11.htm Acesso em 11/04/2009. 
a parte mais significativa de seus trabalhos a respeito da análise da economia: o primeiro é o livro V da Ética a Nicômaco, o segundo é o livro I da Política.

Além disso, a concepção aristotélica da economia balizaram 0 tratamento ocidental às questões econômicas até, pelo menos, o renascimento, com o surgimento do metalismo e das primeiras colônicas na América. $O$ tratamento dado pelo medievo à economia era fortemente aristotélico, bem como, especialmente, o pensamento de Tomás de Aquino. E ainda deve-se considerar que a influência de Aristóteles foi muito além do próprio mundo ocidental, tendo atingido, ainda, toda a região do Oriente Médio.

Ou seja, Aristóteles, como pensador econômico, teve influência prática por mais tempo do que qualquer moderno, em especial aqueles cujas idéias vão de encontro às de Aristóteles. Portanto, em uma época de crise, política, econômica, social, intelectual, e, principalmente, ambiental, uma procura pelo "retorno às raízes" - não apenas no sentido de explicar de onde veio o mundo tal como está, mas especialmente como eram as idéias que vigiam no passado - faz-se necessária e interessante.

É isso que nos propomos a fazer, tomando como base Aristóteles, por sua importância e estatura tão elevadas. Tomaremos sua concepção de economia como paradigma não apenas por sua descomunal influência, mas também por seu acerto em vários pontos fundamentais, que serão devidamente avaliados.

Assim, em se tratando da divisão dos trabalhos em economia que produziu Aristóteles, tem-se que há dois trabalhos principais, , dentre todas as obras sobreviventes de Aristóteles, que tratam do tema da economia e da crematística.

No Ética a Nicômaco, Aristóteles trata da Economia no mesmo livro em que trabalha com a Justiça, discorrendo sobre a justiça nas relações de troca entre os homens, percebendo a economia como parte da ética. 
$\mathrm{Na}$ Política, por sua vez, Aristóteles trata das quatro formas de aquisição: as naturais e justas, o escambo e a compra por meio de um intermédio, a moeda, e as antinaturais e injustas, a troca da mercadoria por dinheiro a fim de se obter mais dinheiro (modo segundo o qual a mercadoria é que é o intermediário, e não o dinheiro), e a mais antinatural e injusta de todas, o empréstimo a juros. Aristóteles diferencia, em suas exposições, a economia, como sendo a ciência prática que objetiva saber usar bem os meios disponíveis para manter e sustentar a casa (oikos) e a pólis, da crematística, como sendo a técnica de simplesmente adquirir riquezas ${ }^{3}$.

Assim, pode-se dizer que, em Aristóteles, a economia se encontra subordinada à ética e à política. Estas devem impor limites e fins para a economia.

Nisso a economia aristotélica se diferencia da moderna, a qual na verdade é a crematística, posto que se preocupa apenas com a geração de riquezas, e não com a finalidade precípua do agir econômico, que é a sustentação da casa e da pólis. A Escola da Análise Econômica do Direito, parece-nos, trabalha com essa perspectiva, a de adquirir riquezas (por meio da sua ênfase na maximização da utilidade), em seu aspecto normativo.

Nossa exposição é no sentido de trabalhar com esta diferenciação relativamente ao Direito, ressaltando o aspecto crematístico inerente à Análise Econômica do Direito, e verificar seu lugar (se houver) dentro do corpo da teoria econômica aristotélica. Nossa análise é puramente teórico-descritiva: queremos demonstrar a existência de uma dimensão crematística, compreendida na teoria econômica de Aristóteles, na Análise Econômica do Direito, e nada mais.

\footnotetext{
${ }^{3}$ Diferenciamos aqui "arte" de "técnica" ("techne"), nos mesmos termos que eram comuns aos filósofos clássicos, no sentido de que a arte tem de ter um fim, e um fim bom, ao passo que a técnica (techne) se preocupa somente com os meios, e não com os fins, sendo "o processo pelo próprio processo", diferenciação esta exposta por Platão, no "Górgias". Nesse sentido, a economia, que se ocupa dos meios necessários à sustentação da casa (oikos) e da pólis, seria uma arte; ao passo que a crematística, como exposição de meios adequados para a aquisição de riquezas, seria uma técnica, posto que não visaria um fim necessário e justo.
} 


\section{A Análise Econômica do Direito}

A escola da Análise Econômica do Direito nasceu nos Estados Unidos da América, em Chicago, tendo suas raízes teóricas nos trabalhos de Ronald Coase $^{4}$, Gary Becker ${ }^{5}$, Guido Calabresi ${ }^{6}$, e Richard Posner ${ }^{7}$ nas décadas dos sessenta e dos setenta. Sendo os três primeiros economistas, e o quarto, Posner, renomado jurista americano.

A escola da Análise Econômica surgiu, relativamente ao tempo, quando da crise da década dos setenta do Estado do Bem-Estar Social. Apareceu como movimento alternativo do Direito norte-americano, que buscava apresentar novas posições e idéias às doutrinas realista ${ }^{8}$ e convencionalista $^{9}$ então dominantes. Difundiu-se por várias faculdades de Direito e de Economia do país, para, então, no alvorecer da década dos noventa, aportar aos países de tradições jurídicas distantes da Common Law, de origens RomanoGermânicas.

Originalmente trabalhava-se apenas com análises dos efeitos econômicos de decisões judiciais e legislações relativas a trustes (antitrustes),

\footnotetext{
${ }^{4}$ COASE, Ronald $\mathrm{H}$. The problem of social cost, in Journal of Law and Economics, Vol. 3 , 1960.

${ }^{5}$ BECKER, Gary. Crime and law enforcement, 1968.

${ }^{6}$ CALABRESI, Guido. Some thoughts on risk distribution and law of torts, in Yale Law Journal, n. 70, 1961, 499.

7 POSNER, Richard. Economic analysis of law. 6 ed. New York, NY, USA: Aspen Publisher's, 2002.

${ }^{8}$ Sob a influência de Oliver Wendell Holmes, os realistas legais mais influentes nos Estados Unidos da América foram Karl Llewellyn, Felix S. Cohen, Arthur Linton Corbin, Jerome Frank, Robert Lee Hale, Herman Oliphant, Thurman Arnold, Hessel Yntema, Max Radin, William Underhill Moore, Leon Green, e Fred Rodell. Resumidamente, o que colocam os realistas legais é que o Direito é por vezes indeterminado nos casos concretos, sendo, na prática, o Direito, aquilo que os juízes e os tribunais determinam, utilizando, para fazê-lo, toda sorte de considerações extralegais. Na Escola da Análise Econômica do Direito, considera-se a eficência econômica um critério passível de adoção para a solução dos casos difíceis e indeterminados.

${ }^{9}$ De Herbert L. A. Hart, ou a versão do positivismo jurídico para o common law, encerrada em seu magnum opus "The Concept of Law" ("O Conceito de Direito"). Entendia que os fundamentos do Direito eram as decisões passadas e a validade das normas jurídicas, referendadas por sua origem juridicamente perfeita.
} 
contratos empresariais, e atividades criminosas $^{10}$. Desenvolvimentos posteriores passaram a colocar seu instrumental a serviço de análises referentes a temas tributários, constitucionais, administrativos, de reparação civil, e também de contratos.

Almeja, a Análise Econômica do Direito, descobrir e esclarecer os efeitos econômicos dos contratos, decisões judiciais e leis, sob a perspectiva da eficiência econômica, de maior utilidade geral. Tem um lado positivo, que trata de análises descritivas, e um aspecto normativo, o qual busca colocar o que se deve e o que não se deve se fazer para que se atinja determinado objetivo.

No que tange a contratos, objetiva, especificamente, a Análise Econômica do Direito, nos dizeres de RICHARD POSNER ${ }^{11}$ :

\begin{abstract}
"O objetivo de um sistema, metodologia, ou doutrina de interpretação contractual é o de minimizar os custos de transação, compreendidos, em sentido amplo, como obstáculos a esforços voluntários de mover recursos para um uso mais valioso. Esses custos podem ser muito grandes quando, induzindo-se as partes a não contratar, eles evitam que os recursos sejam alocados de maneira eficiente. Em razão de os métodos de redução de custos de transação contratuais, como a litigância, são em si mesmos custosos, cuidadosos custos de oportunidade se fazem necessários." [Tradução Livre]
\end{abstract}

Contratos representam situações de interação voluntária entre as partes. O termo "contrato" é utilizado aqui como significando um conjunto de

\footnotetext{
${ }^{10}$ Em especial, quanto a este último aspecto da Análise Econômica do Direito, Gary Becker foi contemplado com o Sveriges Riksbanks pris i ekonomisk vetenskap till Alfred Nobels minne, o chamado "Prêmio Nobel de Economia", em 1992, por seu trabalho acerca da interação e comportamento humanos sob a ótica do instrumental da microeconomia, inclusive até mesmo as atividades criminosas. Alegou, Becker, em seu trabalho, que o criminoso age de forma racional ao praticar a sua atividade, sendo o crime, sob a ótica do agente, uma atividade econômica como outra qualquer, na qual são pesados custos, riscos e benefícios. Daí a conclusão de que a criminalidade pode ser minorada ou majorada de acordo com os estímulos e desestímulos a que está submetida - incluindo-se aí legislações penais mais brandas e mais severas. V. http://nobelprize.org/nobel_prizes/economics/laureates/1992/.

${ }_{11}$ POSNER, Richard. The law and economics of contractual interpretation, In Texas Law Review, Vol. 83, N. 06, 2005. Pg. 1583. Original: "The goal of a system, methodology, or doctrine of contract interpretation is to minimize transaction costs, broadly understood as obstacles to efforts voluntarily to shift resources to their most valuable use. Those costs can be very great when, by inducing parties not to contract, they prevent resources from being allocated efficiently. Because methods of reducing contractual transaction costs, such as litigation, are themselves costly, careful tradeoffs are required."
} 
compromissos interdependentes que gozam de algum tipo de proteção legal ${ }^{12}$. Em se tratando de contratos, temos que seu elemento principal, em termos legais, é o pacta sunt servanda, o princípio da obrigatoriedade do cumprimento dos contratos.

De acordo com tal princípio, as partes não podem eximir-se de sua obrigação voluntariamente pactuada por meio do instrumento contratual, podendo, qualquer uma delas, no caso de infração ou descumprimento por parte de outra, invocar a proteção legal do Estado e exigir o adimplemento daquela obrigação, ressarcimento, ou punição para a parte infratora. "O contrato é lei entre as partes” ${ }^{13}$, como coloca o famoso adágio.

Entretanto, temos que nem todos os compromissos contratuais são efetivamente protegidos pelo Estado. Há aqueles que são simplesmente nulos; nunca adentraram o ordenamento jurídico (por exemplo, um contrato versando sobre a obrigação de um dos contratantes de vender-Ihe uma casa no alémvida). Também existem os ilegais: seu objeto não é reconhecido como juridicamente passível de proteção (contratos de compra-e-venda de drogas ilícitas, por exemplo).

Mas há também aqueles que se situam numa espécie de limiar da proteção legal. São contratos que, em princípio, gozam de proteção jurídica; mas esta acaba por se ver mitigada quando do caso concreto por conta da aplicação de algum princípio, ou pela observância de alguma circunstância de fato, que the retiram, aos olhos do agente encarregado de render-lhes a

${ }^{12}$ RODRIGUES, Vasco. Análise económica do direito: uma introdução. Coimbra, Portugal: Livraria Almedina. 1를. 2007. Pg. 125.

${ }_{13}$ Princípio de origem romana anterior à Lei das XII Tábuas, consagrado no Código Napoleônico, em seu art. 1.134, e repetido por outros ordenamentos, inclusive o brasileiro. Trata-se do princípio da supremacia da vontade levado às suas últimas conseqüências. Também chamado de pacta sunt servanda, representa uma recusa de interferência, por parte do Estado, na vida privada. É um dos princípios mais caros a qualquer ordenamento jurídico de caráter liberal. Muito embora se encontre terrivelmente mitigado atualmente, no Brasil, por conta de crescente intervenção estatal aplicada com o fim de prevenir práticas e situações consideradas abusivas, especialmente na presença de grande disparidade econômica entre as partes contratantes, dá-se que ainda é o princípio norteador das relações contratuais, sem 0 qual não poderia existir o próprio contrato. É possível dizer, até mesmo, que, onde a mão-deferro do Estado não se faz presente, os particulares desrespeitam as limitações impostas pelo Leviatã e aplicam o princípio do pacta sunt servanda em sua totalidade, sem quaisquer restrições. 
proteção estatal, o mérito dessa mesma proteção e a possibilidade de sua ocorrência.

Contratos de longo prazo, por exemplo, ou envolvendo uma obrigação futura, podem acabar por sofrer de disparidades entre as obrigações assumidas por uma das partes e o benefício que esta deverá vir a ter com o pacto. Ou simplesmente uma grande discrepância entre os ganhos auferidos por uma parte e os benefícios colhidos pela outra.

Nesses casos, é muito comum ver-se aplicada, por exemplo, a chamada teoria da imprevisão ${ }^{14}$, dentre outras, como forma de admitir-se o rompimento do contrato ou a sua revisão. Contudo, tais discrepâncias ou disparidades é o que se vê. $\mathrm{O}$ que não se vê ${ }^{15}$ são as conseqüências das decisões judiciais que buscam mitigá-las, uma vez globalmente consideradas.

O rompimento e a reinterpretação de um contrato por conta de uma decisão judicial muitas vezes acaba por trazer conseqüências que vão além dos efeitos visualizáveis entre as partes ${ }^{16}$. O fim do contrato pode ensejar uma desconfiança entre os demais agentes econômicos que tenham pactuado contratos de mesmo tipo daquele que foi forçadamente rompido ou reinterpretado. Como bem observa, por exemplo, CLÁUDIO PETRINI BELMONTE ${ }^{17}$ :

"Assim, com base no exemplo da cadeia de exportação de gado para o Líbano, têm-se diversos outros contratos de compra e venda de

${ }^{14}$ V. GAGLIANO, Pablo Stolze. Algumas considerações sobre a Teoria da Imprevisão. Jus Navigandi, Teresina, ano 5, n. 51, out. 2001.

Disponível em: http://jus2.uol.com.br/doutrina/texto.asp?id=2206. Acesso em: 21 jun 2009.

${ }_{15}$ Citamos em homenagem ao economista francês Fréderic Bastiat (1801-1850), que consideramos como sendo um notável precursor da Análise Econômica do Direito. Bastiat utilizava a frase "o que se vê e o que não se vê" referindo-se às conseqüências perversas, mas ocultas, de leis e de políticas cujos proponentes não enxergavam, preferindo focar-se nos seus efeitos mais imediatos, tendo escrito, ao longo de sua breve vida, vários ensaios versando sobre tal tema. O que se vê pode ser bom, mas o que não se vê não raro implica males muito superiores aos benefícios. Ver BASTIAT, Frédéric. Frédéric Bastiat. $1^{\text {a }}$ ed. Rio de Janeiro, RJ: Instituto Liberal, 1989. Também disponível em: http://www.ordemlivre.org/files/bastiatensaios.pdf. Acesso dia 12 jun 2009.

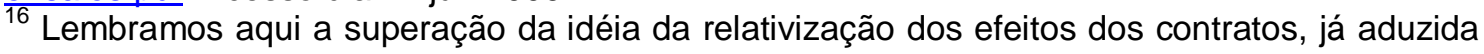
há algum tempo pela doutrina abalizada.

17 Apud COELHO, José Fernando. Contratos agrários: uma visão neo-agrarista. Curitiba: Juruá, 2006. Pgs. 73 e 74. 
gado realizados com os produtores rurais, contratos de intermediação de compra e venda, contratos de transporte rodoviário do gado até o Porto de Rio Grande, contratos aduaneiros, contratos de transporte marítimo, entre outros.

Nesse caso, a hipótese de inadimplemento em um dos elos prejudicaria a cadeia como um todo. $E$, por conseqüência, acarretaria um enorme prejuízo para a economia e para a sociedade, restando demonstrado que os efeitos irradiados dos contratos vão além da relação das partes, por mais que obrigue apenas "A" e "B", já que o não cumprimento dos contratos implica na quebra da finalidade da liberdade de contratar."

Nessas circunstâncias, o custo para se efetuar ou se manter os contratos se eleva. Trata-se de aumento dos custos de contratar (ou custos de transação, tema que será tratado a seguir), gerado pela ação estatal no sentido de proteger determinados contratos de forma diferente da maneira originalmente prevista pelas partes, ou por omissão, pela negativa de proteção estatal frente a esses contratos.

É evidente que há relações contratuais que às quais o Estado não deve render proteção, por ofenderem irreparavelmente a ordem jurídica. Entretanto, face ao nebuloso terreno das conseqüências advindas do rompimento ou da reinterpretação de um contrato, torna-se necessário, na ótica da Escola da Análise Econômica do Direito, analisar os efeitos da ação intervencionista ou da omissão estatais quando do trato com quaisquer contratos.

Quando o julgador, pois, se defronta com um caso no qual há um mínimo de possibilidade no sentido de se romper ou de se reinterpretar um contrato, por conta seja de quaisquer motivos relevantes (como disparidade econômica entre as partes), na verdade está ele fazendo um juízo de pesos entre o valor dado ao pacta sunt servanda e ao outro bem jurídico em questão. Coloca, a Escola da Análise Econômica do Direito, nessas circunstâncias, a seguinte proposição: utilizar o critério da eficiência como forma de traçar uma linha, de onde é possível fazer prevalecer um determinado princípio em detrimento de outro nas relações contratuais.

Assim, tem-se o objetivo da Análise Econômica do Direito, no que toca aos contratos, que é o de responder a estas duas perguntas: 1) "qual o sentido 
da economia do contrato?" e 2) "em relação a quais contratos a proteção jurídica total e efetiva representa um bem?".

Para respondê-las, utiliza-se de instrumental teórico que pode ser resumido a três conceitos básicos. São eles: Escolha Racional, Custos de Transação e Eficiência.

\subsection{A Escolha Racional ou Maximização Racional}

O conceito de escolha racional não se trata da idéia de que os indivíduos sempre fariam escolhas racionais no sentido de correção de suas ações, como poderia entender, primeiramente, um leigo. Por "escolha racional" se entende, simplesmente, que o homem é um ser racional que busca maximizar a sua satisfação. Não presume onisciência ou perfeição de mente e de informações.

Coloca-se, desse modo, que o homem busca maximizar a sua utilidade, desse modo. Por utilidade, dentro da escolha racional, deve-se entender que os agentes escolhem sempre, dentre duas ou mais alternativas, àquela que melhor se adeqüa à sua escala de preferências. O agente é capaz de ordenar as diversas alternativas que se lhe apresentam em função de sua utilidade para si. Nesse sentido, se uma determinada pessoa se vê diante de três alternativas, $\mathrm{A}, \mathrm{B}$ e $\mathrm{C}$, e prefere $\mathrm{A}$ a $\mathrm{B}, \mathrm{B}$ a $\mathrm{C}$, e $\mathrm{A}$ a $\mathrm{C}$, irá escolher $\mathrm{A}$.

Importante ressaltar, nesse ponto, que a utilidade não é objetiva, mas puramente subjetiva. A utilidade de um homem em relação a algo é única, e não pode ser comparada à de outro em relação à mesma coisa. Não existem comparações interpessoais de utilidade e de escalas de preferência $^{18}$.

\footnotetext{
${ }^{18}$ No que a Ciência Econômica moderna, bem como, conseqüentemente, a Análise Econômica do Direito, se diferenciam de uma de suas raízes, o utilitarismo de Jeremy Bentham. Bentham afirmava, categoricamente, em seu Introduction to the Principles of Morals (1780), que a utilidade de cada um poderia ser medida com precisão e comparada à de outrem, possibilitando, assim, políticas maximizadoras de utilidade geral. Tal concepção é rejeitada atualmente, especialmente após a emergência do Marginalismo de Menger e Walras.
} 
A utilidade depende do grau de satisfação que o indivíduo espera obter de uma determinada escolha. Esse grau, por sua vez, provém de sua análise subjetiva acerca dos custos e benefícios que terá com essa escolha.

Como esses custos representam a abdicação de uma escolha em prol de outra (por exemplo, colocar um real na poupança ou utilizar esse mesmo um real para comprar um doce), temos que as escolhas que o indivíduo faz são uma mera comparação subjetiva de utilidade, na qual se pesam os custos e os benefícios de uma escolha e de outra. A isso se chama "custo de oportunidade".

A Escolha Racional, portanto, nada mais é do que algo intrínseco à ação racional do indivíduo. Qualquer escolha que fizer será feita de acordo com o grau de satisfação superior que espera daquela escolha em particular em detrimento de outras possíveis, as quais se situam, na sua escala de valores, em posição inferior à que efetivamente fez.

\subsection{Os Custos de Transação}

Custo de transação é um conceito imprescindível para se entender a economia do contrato. Foi criado - ou descoberto - pelo economista Ronald Coase, na década dos setenta, no artigo intitulado "The Nature Of The Firm", ainda que, à época, ainda não tivesse dado ao conceito efetivamente esse nome.

Custos de transação, na definição econômica, são todos os custos envolvidos para a realização ou feitura de uma troca, ou de um contrato. Sob uma perspectiva mais ampla, são todos os custos decorrentes das instituições e da interação humana, no tempo ${ }^{19}$, para se efetuar uma determinada transação. Envolvem os custos de feitura, litigância, manutenção, etc. Até mesmo os custos de transporte podem adentrar a equação, a variar de acordo com o tipo de contrato em questão.

\footnotetext{
${ }^{19}$ Ver COASE, Ronald. The nature of the firm. Oxford, U.K.: Blackwell Publishing. Economica, New Series, Vol. 4, No. 16, Nov. 1937, pp. 386-405.
} 
De acordo com Williamson ${ }^{20}$, há dois tipos de custos de transação que afetam os agentes econômicos: 1) os custos pré-contratuais de negociar e fixar os termos dos contratos; 2) os custos de manutenção da relação contratual, custos de eventual litigância, e de renegociação.

Os custos de primeiro tipo costumam ser mais comuns em contratos incertos, nos quais a realização do pactuado depende de condições que as partes não sabem ao certo quais são ou se vão mesmo se dar de acordo com o esperado por cada uma delas.

Custos do segundo tipo, por sua vez, são mais freqüentes em contratos de longo prazo, com obrigações a serem realizadas por ambas as partes no decorrer do tempo. Em especial, os custos de litigância, no Brasil, se mostram especialmente custosos, como é de conhecimento comum. São deste tipo os custos de transação mais comuns e mais fáceis de ocorrer nos contratos agrários, dado o fato de que são de prestação contínua e geralmente de longo prazo.

A existência de cláusulas obrigatórias pode ou não implicar custos de transação reduzidos. Sim, no caso de servirem para reduzir os custos iniciais e também evitar litigâncias; não, caso sofram de má-redação e/ou levem à revisão judicial dos contratos, por falhas interpretativas ou por imposição de termos que gerarão problemas no futuro.

\subsection{A Eficiência}

Em um sentido, considerando-se não um bem ou serviço em particular, mas a totalidade deles, equilíbrio pode ser definido como o padrão de interação entre indivíduos que é alcançado quando todos os agentes estão maximizando sua utilidade simultaneamente, e de forma que nenhuma alteração no quadro possa implicar em incremento nessas utilidades. A situação descrita aqui é o

\footnotetext{
${ }^{20}$ WILLIAMSON, Oliver. The economic institutions of capitalism. $1^{\text {a }}$ ed. New York, NY, USA: The Free Press, 1985. Pg. 388.
} 
chamado Ótimo de Pareto $^{21}$. Ocorre quando se atinge uma situação na qual não é possível aumentar a utilidade de mais ninguém sem prejudicar a outrem.

Essa é a situação que leva ao conceito de Eficiência. Diz-se que uma determinada troca é eficiente quando vai ao encontro do Ótimo de Pareto - isto é, incrementa a utilidade, em direção ao equilíbrio geral. É importante ressaltar aqui, novamente, que a utilidade é individualmente considerada.

Por isso, uma situação de Ótimo de Pareto não é necessariamente justa, em termos de igualdade de condições das partes. Significa apenas que é eficiente economicamente. Ou, de acordo com VASCO RODRIGUES ${ }^{22}$ :

\begin{abstract}
"Dizer que uma situação é Pareto-Eficiente, é um óptimo de Pareto, não é o mesmo que dizer que é justa, boa ou correcta. Por exemplo, se duas pessoas famintas tiverem que distribuir entre si dois quilos de arroz e uma se apoderar e toda comida, a situação resultante é um óptimo de Paeto: não é possível aumentar a satisfação da pessoa que não recebeu arroz sem prejudicar a que dele se apropriou. No entanto, presumivelmente, a maioria das pessoas não considerariam essa distribuição justa."
\end{abstract}

Dentro do exemplo citado por ARAÚJO, se temos dois sacos de arroz, para serem distribuídos entre duas pessoas, e uma delas se apropriar de ambos, justa ou injustamente, ter-se-á um Ótimo de Pareto, pois não se pode tirar um saco de arroz da pessoa que se apropriou dos dois sem prejudicá-la. Não se fazem análises interpessoais de utilidade por sua precariedade. Não seria possível dizer que a utilidade maior seria atingida se a cada pessoa, nesse caso, fosse dado um saco de arroz, se, por exemplo, fossemos informados de que uma delas é solteira, e a outra, casada e com cinco filhos.

Em resumo: uma dada situação é eficiente quando não pode receber melhoramentos, ou quando as alternativas são mais custosas do que o status quo.

\footnotetext{
${ }^{21}$ Vilfredo Pareto (1848-1923) foi um economista, sociólogo e engenheiro italiano.

${ }^{22}$ RODRIGUES, Vasco. Análise económica do direito: uma introdução. Coimbra, Portugal: Livraria Almedina. 1를. Ed., 2007. Pg. 27.
} 


\section{A economia em Aristóteles}

A elaboração, por Aristóteles, de seu conceito de economia, começa pela introdução do que é o homem, no que define o homem como sendo um zoon politikon, isto é, um animal político ${ }^{23}$, posto que o homem só se realizaria como indivíduo dentro da comunidade política, sendo, o homem, fora dela, "ou um bruto, ou uma divindade" ${ }^{24}$. Não existiria o homem fora da comunidade política, senão como uma besta, e certamente não como humano. Diz Aristóteles: "a cidade é, por natureza, anterior ao indivíduo, porque se um indivíduo separado não é auto-suficiente, permanecerá em relação à cidade como as partes em relação ao todo"25.

Para a realização do homem, este deve buscar o seu bem viver. Por outro lado, o homem não vive isolado dos demais. Portanto, para a realização do bem do indivíduo, deve-se procurar, também, o bem da pólis, que é o campo da realização do político. Isto é, deve-se procurar o bem comum.

No entanto, é condição necessária para a realização do bem comum almejado pela pólis a provisão de bens para que se proceda à consecução dos projetos de bem comum, visando a melhora da pólis e dos indivíduos que a compõem. Aí, tem-se, como função do caracter político do homem, que o faz ser um zoon politikon, o caracter econômico do homem, que o faz ser também um animal econômico.

O homem, portanto, para Aristóteles, tem uma dimensão produtora, econômica, voltada à finalidade de sustentar a si mesmo e à pólis, a fim de poder promover o seu próprio bem e o bem comum.

Torna-se mais fácil a compreensão do sentido da economia, em Aristóteles, por meio da análise da etimologia da palavra montada por Aristóteles. Economia é "oekonomia", que é uma junção dos termos "oikos",

\footnotetext{
${ }^{23}$ ARISTÓTELES. Política. São Paulo: Martin Claret, pg. 14

${ }^{24}$ Ibidem, pg. 15.

${ }^{25}$ Ibidem, pg. 14.
} 
que se refere à casa, à unidade familiar, e de "nomos" que se refere à casa, fragmento inicial da teoria econômica de Aristóteles.

Assim, Aristóteles começa a elaboração de sua teoria econômica não por conta de uma espécie de adesão precursora ao individualismo metodológico $^{26}$, e sim porque a casa é a unidade básica o primeiro nível da vida social. É na casa que o homem passa a maior parte do seu tempo, e são relativas à casa boa parte das relações entre os homens. Dessa forma, a provisão de bens para a casa não poderia ter apenas a finalidade de mantê-la, isto é, de mera subsistência, mas deveria estar de acordo com as necessidades do vínculo familiar, razão de ser da casa.

No entanto, para Aristóteles, como já afirmado, o homem é um animal político, um zoon politikon. Isso significa que o homem só tem existência individual enquanto membro da Pólis, e só é capaz de atingir a felicidade e a finalidade de sua existência, representadas na eudaimonia ${ }^{27}$, dentro da Pólis, e nunca fora dela.

Logo, a boa administração da casa (isto é, a mantença da unidade familiar de acordo com o fim encerrado em sua essência) serve a um outro fim justo, que é a manutenção da Pólis. Contudo, a administração da própria Pólis, como entidade composta pela reunião de várias casas, requer, ela própria, manutenção e finalidade.

É nesse sentido que entra a economia, como arte de bem administrar as riquezas da pólis, não só no sentindo de sua manutenção, de sua existência, mas sim na melhora da vida de seus cidadãos. Não compreendido, porém, nisso, tão somente o aspecto quantitativo, que o utilitarismo subjetivista

\footnotetext{
${ }^{26}$ Termo - e a alegação é controversa, favor notar-se - que se diz ter sido cunhado por Carl Menger, na sua obra "Investigations into the Method of the Social Sciences with Special Reference to Economics". Na economia, se trata de reduzir o objeto de análise ao menor elemento possível - no caso desta ciência, o indivíduo.

${ }_{27} \mathrm{O}$ bem viver, de acordo com as virtudes e a razão prática. Ver ARISTÓTELES, Ética a nicômaco. São Paulo: Martin Claret, 1097b, pg. 25.
} 
moderno ${ }^{28}$ iria, posteriormente, enfatizar, mas sim o qualitativo, no sentido de servir a um fim cívico, de tornar a pólis melhor, de acordo com um ideal de bem comum. Não se trata da simples melhora das condições de vida, e sim de uma orientação para o bem viver.

A economia, em Aristóteles, é uma ciência bastante diferente do uso moderno, que se refere à ciência que estuda as relações de produção, distribuição e consumo de bens e serviços. A economia aristotélica é mais abrangente: inclui o uso desses bens e serviços e todo o conjunto de relações segundo as quais foram criados ou deverão ser utilizados.

A concepção de economia de Aristóteles poderia ser chamada, a fim de evitar confusões para com a utilização moderna da palavra, de metaeconomia, posto que se refere à uma ciência que estaria acima da economia propriamente dita, estando esta Ihe subordinada, e que Ihe geraria diretrizes e princípios e Ihe estabeleceria limites epistemológicos e metodológicos. Entretanto, em respeito à terminologia utilizada por Aristóteles, nos furtaremos de trabalhar com tal expressão ao tratarmos de sua teoria.

Para Aristóteles, a economia é necessariamente parte da Ética, e subordinada à Política. Portanto, o uso a que devem ser direcionadas às riquexas deve ser bom; e, de outro, no âmbito da pólis, cabe à política, em função da ética, de forma não raro casuística, determinar de que forma deverão ser obtidas e usadas as riquezas. Isso não significa que é o Estado que deve, pura e simplesmente, planejar a economia: em verdade, ARISTÓTELES ${ }^{29}$ se posiciona francamente em favor da propriedade privada, porém com limites ao seu uso:

"A sequência natural das idéias traz a questão da propriedade. Qual será a lei a propósito das propriedades no projeto da melhor

\footnotetext{
${ }^{28}$ Referimo-nos ao utilitarismo subjetivista de Menger, Jevons e Walras, por eles desenvolvido no séc. XIX e evolução das idéias utilitaristas de Jeremy Bentham. De acordo com John Moser (The Origins of the Austrian School of Economics, Humane Studies Review, 11: 1), a teoria subjetiva do valor pode ser resumida na seguinte frase: para que uma coisa possua valor, deve ser, ao mesmo tempo, útil e escassa, e de forma que a sua utilidade se refira à sua capacidade de satisfazer às necessidades, subjetivamente consideradas, de qualquer indivíduo.
}

${ }^{29}$ ARISTÓTELES. Política. São Paulo: Martin Claret, pgs. 43-44. 
constituição? Elas serão comuns ou pessoais? (...) Se as terras são lavradas por outros que não os cidadãos, outra será a questão, e mais fácil; porém, se os que os cultivam o fazem por conta própria, a razão do interesse trará maiores dificuldades. O desnível entre os trabalhos e os prazeres despertará, evidentemente, o descontentamento dos que trabalham muito e pouco recebem, contra os que pouco trabalham e recebem muito. (...) A comunidade dos bens desperta, portanto, estes e outros inconvenientes. (...) ...o atual processo de posse que se recomenda pela autoridade dos usus e pela prescrição de leis sábias deve oferecer grande vantagem. Englobará os benefícios dos dois sistemas, quer dizer, da propriedade possuída em comum e da posse individual, concomitantemente. (...) .... valor da propriedade será muito mais aumentado, pois cada um se esforçará integralmente como se se tratasse de uma coisa exclusivamente sua. (...) ...tendo cada cidadão sua propriedade particular, põe-na em serviço dos amigos, e dela se serve em parte como de um bem comum. (...) É preferível, portanto, que os bens sejam pertencentes a particulares, porém que se tomem propridedes comuns pelo uso que se faz deles." [GRIFO NOSSO]

Nessa esteira, isto é, no relativo ao uso da propriedade para e de acordo com o bem comum, essencial ao conceito de Economia em Aristóteles é a distinção entre valor de uso e valor de troca. Aristóteles inicia esta sua exposição com o exemplo de um calçado ${ }^{30}$, mencionando o seu uso próprio, qual seja, o de calçar e proteger os pés. Isso seria o seu valor de uso. Como coloca Aristóteles ${ }^{31}$ :

"Comecemos pela seguinte observação: cada coisa que possuímos tem dois usos, dos quais nenhum repugna a sua natureza; porém, um é próprio e conforme a sua destinação, outro desviado para algum outro fim. Por exemplo, o uso próprio de um sapato é calçar; podemos também vendê-lo ou trocá-lo para obter dinheiro ou pão, ou alguma outra coisa, isto sem que ele mude de natureza; mas este não é o seu uso próprio, já que ele não foi inventado para o comércio. O mesmo acontece com as outras coisas que possuímos. A natureza não as fez para serem trocadas, mas, tendo os homens uns mais, outros menos do que precisam, foram levadas por este acaso à troca."

Ou seja, para Aristóteles, é o valor de uso das coisas que as torna passíveis de serem trocadas. Nesse sentido, um sapato torna-se um objeto desejável numa troca por causa de sua utilidade, isto é, a proteção dos pés, ao ser calçado.

\footnotetext{
${ }^{30}$ ARISTÓTELES. Política. São Paulo: Martin Claret, pg. 25.

${ }^{31}$ Ibidem, pg. 25.
} 
Assim, pode-se resumir o conceito de valor de uso na proposição de que o valor de uma coisa, para uma pessoa, deriva de sua utilidade para o bem de alguma pessoa. Este valor não é subjetivo, entretanto: o valor é objetivo e refere-se á utilidade intrínseca da coisa.

Desse modo, a troca, de uma coisa por outra, de acordo com a natureza, deve referir-se sempre ao seu valor de uso; isto é, é a utilidade da coisa que faz com que os homens a desejem e a troquem por outras, que para si também sejam úteis. Não é a natureza das coisas que leva os homens a trocarem-nas, e sim as diferentes necessidades dos homens, tão variáveis quanto eles próprios. Nas palavras de Aristóteles, "A natureza não as fez para serem trocadas, mas, tendo os homens uns mais, outros menos do que precisam, foram levadas por este acaso à troca" ${ }^{32}$.

Por outro lado, nisso Aristóteles distingue a troca necessária da supérflua e antinatural. Esta não é nenhuma outra senão o comércio pelo comércio; ou, na fórmula marxiana mais conhecida, D-M-D, ou seja, dinheiro pela mercadoria, a fim de que esta seja, por sua vez, trocada por valor superior ao inicial, parte do qual deverá ser usada para adquirir novas mercadorias para, por sua vez, também serem trocadas por soma superior às que foram compradas.

O comércio pelo comércio é considerado por Aristóteles como sendo antinatural. Na citação anteriormente referida, Aristóteles alude à distinção entre o comércio enquanto troca bilateral e ao comércio por dinheiro. A isto corresponde o valor de troca: a quantia pela qual uma coisa pode ser trocada por outra.

O valor de uso, por sua vez, e isso é de extrema relevância, não necessariamente se traduz em valor de troca tão considerável quanto à sua utilidade intrínseca (isto é, o seu valor de uso). Remetemo-nos ao exemplo do diamante e da água: o valor de troca do primeiro é muito maior do que o da

\footnotetext{
${ }^{32}$ Ibidem, pgs. 25-26.
} 
segunda, no entanto o seu valor de uso é praticamente nulo, ao passo que o da água está entre os mais elevados dentre todas as coisas ${ }^{33}$.

O conceito que Aristóteles dá à riqueza se refere ao sustento da casa e da pólis. Nesse sentido, a riqueza só é útil à medida em que serve para o sustento da pólis. Logo, a riqueza verdadeira é aquela que se refere às coisas com alto valor de uso, e não de troca.

Ademais, parte ou dimensão da economia se preocupa apenas com a obtenção da riqueza, e a economia, como um todo, em como melhor usá-la. Aristóteles considerava a técnica de adquirir riquezas, como uma parte da economia. Contudo, essa técnica para ser natural, e portanto boa, em relação à economia, deveria se ocupar apenas dos bens de primeira necessidade, e não dos supérfluos. A verdadeira riqueza é aquela que serve ao próprio sustento; é a riqueza cujo fundamento é o valor de uso dos bens que a compõem, e não o seu valor de troca.

Assim, se de um lado desejável e necessária é a parte da economia que busca encontrar os meios necessários à manutenção da casa, e da pólis, porém sem considerar a si mesma como fim último, de outro é indesejável e antinatural a parte da economia que se ocupe exclusivamente com o valor de troca dos bens que procura obter. Se, de um lado a economia propriamente dita, como um todo, se preocupa com os fins a que se destinam as riquezas, de outro é uma parte dela que deve se ocupar da obtenção desses bens; essa parte, denomina-se crematística.

\footnotetext{
${ }^{33}$ Situação hipotética muito comentada por economistas oitocentistas. O seu criador foi Adam Smith, entretanto tal posição é disputada, tendo em vista a sua citação por Locke e John Law, entre outros.
} 


\section{A crematística}

Uma vez exposto o que Aristóteles entende por economia, parte-se para a explicação do que entende por crematística. Em essência, crematística, para Aristóteles, é a mera "arte ${ }^{34}$ de adquirir riquezas ${ }^{35 " ;}$, no que difere da economia, que se refere a como melhor utilizá-las.

Como, para Aristóteles, as causas finais têm maior importância que as causas eficientes, tem-se que a crematística seria inferior à economia, posto que, como técnica, referente à produção, estaria subordinada a uma ciência do saber prático, que, no caso, é a economia. A finalidade última, pois, da economia, seria mais importane que a da crematística, que seria apenas um meio para àquela.

No que toca à crematística, coloca Aristóteles duas formas segundo as quais se dá a aquisição de riquezas, uma natural e outra contrária a natureza. As formas naturais de aquisição são aquelas sancionadas pela natureza do homem e de acordo com o bem. Por exemplo, a agricultura, a caça, a pesca, a coleta e até a guerra, a primeira uma atividade produtiva, e as demais atividades extrativistas, para fins de subsistência direta do próprio trabalho. Este ponto é de suma importância, posto que dentre as formas ditas naturais, Aristóteles considera somente aquelas que não advêm do comércio, mas da produção, da propriedade, e por ela limitadas ${ }^{36}$. Nesse sentido, ARISTÓTELES ${ }^{37}$ :

"Existe, porém, outro modo de conquista a que se denomina principalmente, e com razão, a arte de adquirir; é o que não impõe fronteiras à riqueza, e que, dada a vizinhança que os aproxima, em geral se acredita ser aquele de que acabo de falar. Não o é, ainda que dele não esteja por demais afastado: um é natural, o outro não

\footnotetext{
${ }^{34}$ Arte, aqui, corresponde ao sentido platônico de "técnica", já mencionado.

${ }^{35}$ ARISTOTELES. Política. São Paulo: Martin Claret, pg 27.

${ }^{36}$ Ibidem, pg 25.

${ }^{37}$ ARISTÓTELES. Política. São Paulo: Martin Claret, pg 24.
} 
provém da natureza e é, sobretudo, o resultado da inteligência e de uma certa arte..$^{38}$

As formas não naturais a que se refere Aristóteles são aquelas que não estão ligadas diretamente à origem na propriedade, e que não são, portanto, necessárias e limitadas. A crematística antinatural, nesse sentido, está encerrada nessa separação: o necessário do supérfluo, considerando os recursos necessários como sendo, somente estes, "a verdadeira riqueza"39.

Para Aristóteles, pois, somente é verdadeira riqueza aquilo que se presta a um bom uso, um uso necessário ou útil. É aí que se faz a separação entre a crematística natural, "boa", e a crematística antinatural, "ruim". Esta teria por função não a geração de riquezas segundo um bom fim, necessário e útil, e sim um fim ruim. A riqueza é boa segundo a destinação que a ela é dada.

Aristóteles reconhece na criação da moeda um expediente necessário, e bom, para que os homens pudessem ter um meio de troca, segundo o qual poderiam comerciar seus bens e satisfazer suas diferentes necessidades de acordo com as suas diferentes produções. Nesse sentido, coloca Aristóteles ${ }^{40}$ :

\begin{abstract}
"Convencionou-se dar e receber nas trocas matéria que, por si mesma útil, fosse de fácil condução nas diversas circunstâncias da existência, como o ferro, a prata, inúmeras outras substâncias das quais foram determinadas inicialmente somente as dimensões e o peso, e, finalmente, foram marcadas com um sinal impresso para obviar o inconveniente das medições frequentes; a marca passou à figura como uma identificação de qualidade. Quando a necessidade da permuta trouxe a invenção da moeda, novo ramo apareceu na ciência de enriquecer: o comércio varejista, que talvez tenha sido, a princípio, feito de maneira muito singela, porém no qual a experiência introduziu mais arte depois, quando se ficou melhor conhecendo onde deveriam ser procurados os objetos da permuta e o que era necessário para se ter maior lucro. Eis a razão por que a ciência de enriquecer passou a ter como finalidade o dinheiro cunhado, sendo o seu desideratum principal ensinar os modos de o conseguir em
\end{abstract}

\footnotetext{
${ }^{38}$ Na tradução de António Campelo Amaral e Carlos de Carvalho Gomes, publicada pela editora Vega de Lisboa, os termos aparecem mais claramente descritos, efetivamente se referindo, Aristóteles, à crematística e à economia de forma expressa, a ver: "existe, porém, outro modo de aquisição a que a maior parte chama, e justamente, crematística, em relação à qual parece não existir limite nem de riqueza nem de propriedade: muitos supõem que é idêntica à anteriormente mencionada, devido à afinidade entre ambas: na realidade, não é idêntica à que referimos mas também não está muito afastada; uma é natural, a outra não, provindo mais de uma certa forma de engenho e arte."

${ }^{39}$ Aristóteles. Política. São Paulo: Martin Claret, pg 25.

${ }^{40}$ Ibidem, pg. 26.
} 
grande quantidade; é efetivamente esta ciência que traz a abastança e as grandes fortunas."

Por outro lado, também serviu, a introdução da moeda, para que se tornasse possível a referida acumulação D-M-D, isto é, o dinheiro pelo dinheiro, com a mercadoria como intermediário. A partir de então, riqueza passou a ser sinônimo de grande quantidade de dinheiro; entretanto, no esquema natural, isto é, M-D-M, no qual o dinheiro é que é o intermediário, e não a mercadoria, estaria compreendido que riqueza é a grande quantidade de bens, e não necessariamente a grande quantidade de dinheiro ${ }^{41}$.

Esta última seria a crematística antinatural, de acordo com Aristóteles, isto é, a aquisição de dinheiro apenas para obter mais dinheiro. Trata-se de uma degeneração do sistema inicial da moeda, cuja finalidade teria sido a de facilitar trocas não contrárias à natureza entre os homens.

Este sistema inicial, isto é, baseado na aquisição de riquezas, tinha por imperativo a necessidade de que estas tivessem um fim, qual seja, o bom uso, de acordo com as carências da casa e da Pólis. A degeneração, por outro lado, faz com que a aquisição de riquezas se torne um fim em si. Nesse sentido, coloca Aristóteles ${ }^{42}$ :

\begin{abstract}
"O fim a que se propõe o comércio não tem limite determinado. Ele compreende todos os bens que se podem adquirir; mas é menos a sua aquisição do que seu uso. O objeto da ciência econômica; esta, portanto, está necessariamente restrita a uma quantidade determinada. Não ignoramos que neste ponto a teoria é desmentida pela prática. Todos, e principalmente os comerciantes, amam 0 dinheiro, não julgam ter o suficiente e sempre acumulam. De um ao outro, é apenas um passo."
\end{abstract}

A crematística é uma técnica de aquisição de riquezas que tem como finalidade, assim, no sistema com moeda, a obtenção de dinheiro, que deverá ser usado para trocas. No entanto, essa técnica de aquisição deve ter por

\footnotetext{
${ }^{41}$ Famosa posição análoga é a de Adam Smith, segundo a qual o que faz a riqueza de uma nação é a quantidade de bens que possui, e não os metais. V. SMITH, Adam, "An Inquiry into the Nature and Causes of the Wealth of Nations", livro IV.

${ }^{42}$ Aristóteles. Política. São Paulo: Martin Claret, pg 26.
} 
finalidade a obtenção de riquezas - e é aí que reside a diferença entre a crematística natural e a crematística antinatural.

Importante ressaltar, nesse ponto, que a crematística não é considerada algo ruim. É o seu mau uso, ou a permissão de que a crematística passe a ocupar o território da economia, como se fosse toda ela, que é condenada por Aristóteles. A crematística em si, como técnica de obtenção de riquezas, é necessária ao sustento da casa e da pólis.

Ocorre que a crematística fornece os meios para a obtenção de dinheiro em abundância, mas não está preocupada com o seu devido uso. Esse campo é o da economia. A crematística natural, portanto, apenas serve de instrumento - técnica - para que a economia, que é a ciência que trata do bom uso das riquezas disponíveis - possa operar. No que fugir disso, a crematística torna-se antinatural.

Para Aristóteles, pois, dá-se que a crematística antinatural é aquela que ignora essa obrigação, ou que a encampa. A crematística antinatural toma o lugar da economia, ou ignora a sua posição; daí o seu erro. Dá-se, pois, que o produto da crematística antinatural, ou, o comércio pelo comércio, é nada mais senão a produção ilimitada de riquezas monetárias. No entanto, a economia, por definição, trata de encontrar o bom uso para riquezas reais, limitas. Logo, há uma contradição. Nesse sentido, Aristóteles ${ }^{43}$ :

\footnotetext{
"Frequentemente, tem-se como riqueza a abundância de metais cunhados, visto que tal abundância indica o objeto da ciência e da indústria e do pequeno comércio. De outro modo, tem-se a moeda como uma inconsequente brincadeira sem qualquer base natural, visto que os mesmos que dela se utilizam podem estabelecer outras convenções, e a moeda deixará de ter valor ou utilidade, e um homem rico em metais cunhados poderá ter falta de gêneros de primeira necessidade. Esquisita riqueza aquele que, por maior que ela seja, não pode impedir a seu possuidor de morrer de fome - como aquele Midas de que fala a fábula, cujo desejo de possuir mudava em ouro todas as iguarias que Ihe serviam."
}

${ }^{43}$ ARISTÓTELES. Política. São Paulo: Martin Claret, pg 26. 
Aristóteles não condena a troca monetária e sim, mas apenas aquela cujo único objetivo é a produção ilimitada de riqueza monetária. O dinheiro, a moeda, deve servir apenas como intermediário entre as trocas, e não como fim destas.

A crematística não se preocupa com o uso das riquezas, mas apenas com a sua obtenção. No momento em que a obtenção de dinheiro passa a ser a única preocupação, a crematística passa a ocupar o lugar da economia porém sem fornecer um substituto à altura para as suas funções. O que, de todo modo, seria absolutamente impossível: se o dinheiro não possui qualquer natureza, senão a de intermediário, não se poderia encontrar qualquer outro uso para ele senão o de continuar a servir de intermediário. A crematística, elevada à posição de economia, não tira ou altera a natureza do dinheiro, mas subverte a sua função. De meio de troca, passa a ser fim.

Na mesma esteira, Aristóteles também condena a instituição dos juros. A moeda seria, para Aristóteles, apenas um veículo de trocas; não poderia ter o condão, portanto, de gerar riqueza, ainda que apenas monetária, isto é, também de valor de troca.

Nisso é possível que Aristóteles tenha se enganado, pois, conforme críticos que se the seguiram, como BÖHM-BAWERK ${ }^{44}$, a instituição dos juros nada mais é do que um pagamento que se faz pelo tempo de gozo do dinheiro que se retira do credor, com o empréstimo que o priva (temporariamente, mas também, em maior ou menor grau, contingencialmente) do dinheiro. Por conseguinte, e isto dentro da própria concepção aristotélica de economia, se o tempo tem de fato algum valor de uso - e supõe-se que o tenha - então a sua troca seria justa, bem como, necessariamente, o pagamento pela mesma, sob a forma de juros.

As consequências práticas da encampação, pela crematística, do campo da economia, em Aristóteles, são vastas. Primeiramente, ocorre uma alienação

44 BÖHM-BAWERK, Eugen von. Teoria da exploração do socialismo-comunismo. São Paulo: Editora José Olympio, 1987. 
na função da atividade econômica. De forma de buscar o auto-sustento, que, por definição, é limitado, passa a ser um fim em si mesma, e ilimitada.

O homem perde, portanto, a noção de que aquilo que visa obter com a atividade econômica deveria servir a um fim que não a obtenção de mais riquezas, mas o seu bem viver. Em outras palavras, o homem passa a adquirir riquezas apenas com a finalidade de adquirir ainda mais riquezas.

Nesse sentido, interessantes são as palavras de E. F. Schumacher, que colocou que, muito embora a produtividade e a produção tenham crescido exponencialmente no último século, em todas as áreas econômicas, a demanda bens, nos países já então ricos, que antes era satisfeita com o nível de produção anterior, aumentou na mesma função da produção. Coloca o economista alemão ${ }^{45}$ :

\begin{abstract}
"A pergunta para iniciar minha investigação é evidentemente esta: há o bastante para fechar o círculo? Imediatamente deparamo-nos com uma dificuldade séria: o que é "bastante"? Quem pode nos explicar? Por certo não será o economista que busca o "crescimento econômico" como o valor máximo, e, por conseguinte, não concebe o "bastante". Há sociedades pobres que têm excessivamente pouco; mas, onde está a sociedade rica que diga: "Chega! Temos bastante"? Não existe nenhuma."
\end{abstract}

Assim, o uso do dinheiro deixa de se reportar à troca segundo as necessidades. Para Aristóteles, isso está em desacordo com o bem viver, e se explicaria pela atenção exclusiva, de parte dos homens, ao mero viver, isto é, ao atendimento aos seus prazeres. Nesse sentido ${ }^{46}$ :

“(..)Da mesma forma, parece necessário que a economia tenha um limite em toda a riqueza, ainda que, como se observa, aconteça frequentemente o contrário. Efetivamente, todos aqueles que buscam enriquecer aumentam indefinidamente a quantidade de dinheiro cunhado que possuem. Isso advém da afinidade de ambas as ciências, pois os meios não são iguais para ambas. (...) O objetivo de uma é a posse, o de outra o aumento dos objetos possuídos, de maneira tal que muitos pensam que o acréscimo da riqueza é o objetivo da ciência econômica, e permanecem na crença de que é necessário manter ou aumentar sem imites o que têm em metais

\footnotetext{
${ }^{45}$ SCHUMACHER, E. F. O negócio é ser pequeno. São Paulo: Círculo do Livro, 1973, pgs. 21 e 22.

${ }^{46}$ ARISTÓTELES. Política. São Paulo: Martin Claret, pg 27.
} 
cunhados. A razão dessa disposição do espírito está em que se pensa em viver, não em bem viver; e, sendo sem limites esse desejo, busca-se multiplicar indefinidamente os meios de o conseguir. Os mesmos que aspiram ao bem viver buscam também os prazeres do corpo, e, parecendo firmarem-se tais prazeres na aquisição da fortuna, nada mais fazem senão procurá-la."

Assim, a crematística, elevada à condição de todo, isto é, como se fosse, ela própria, a economia, e não mera parte dela, leva à subversão do bem viver em relação ao homem que a pratica. Na família, leva à desagregação, pela preocupação com bens supérfluos, e não com as necessidades do núcleo familiar. E, de outro, se também tornada prática institucional, isto é, chancelada pela pólis, e praticada pelos seus cidadãos nos assuntos que lhe disserem respeito, pode levar à sua ruína. 


\section{CONCLUSÃO}

Há, sem dúvida, semelhanças entre a Escola da Análise Econômica do Direito e a teoria econômica de Aristóteles. Primeiro, como já foi colocado, dáse que a Escola da Análise Econômica do Direito trabalha sob a perspectiva da maximização da utilidade.

Isso significa, essencialmente, que, de um ponto de vista descritivo, a Análise Econômica do Direito tentará explicar os institutos jurídicos e o seu funcionamento sob uma perspectiva utitarista e economicista. Em resumo, dirá e tentará demonstrar que um determinado instituto jurídico é de tal forma porque é mais eficiente que seja assim do que qualquer das alternativas - essa sendo uma potencial explicação. A teoria econômica de Aristóteles nada tem a declarar acerca desse aspecto da Análise Econômica do Direito, nos parece.

Por outro lado, sob um ponto de vista normativo - isto é, do que se deve fazer acerca de um determinado instituto jurídico, ou idéias acerca da criação de um determinado instituto - o critério de maximização de utilidade, da Análise Econômica do Direito, torna-se pertinente, no que diz respeito à teoria econômica de Aristóteles. Ocorre, pois, que ali, assume, a Análise Econômica do Direito, uma dimensão crematística.

Parece-nos que o instrumental descritivo da Escola da Análise Econômica do Direito tem bastante acerto, isto é, consegue explicar muitos aspectos da realidade, tanto de um ponto de vista jurídico quanto econômico de forma bastante superior à teorias convencionais ${ }^{47}$. Sendo esse realmente 0 caso - e nos parece que seja - fica claro que o Direito tem, indubitavelmente, uma dimensão crematística (se é possível, pois, explicar a ocorrência de fenômenos jurídicos por meio de uma explicação ao menos parcialmente

\footnotetext{
47 Citamos como exemplo o caso da polêmica acerca da massiva revisão judicial dos contratos de financiamento de safra de soja do período de 2002 a 2004 no estado de Goiás, remetendo ao trabalho realizado por LUCIANO BENETTI TIMM, qual seja, " Direito, economia e a função social do contrato: em busca dos verdadeiros interesses coletivos protegíveis no mercado do crédito. Disponível em http://www.viadesignlabs.com/lawandeconomics/Funcao Social Contrato.pdf.".
} 
econômica, é porque esses fenômenos necessariamente contam com uma dimensão crematística).

A questão que permanece, no entanto, é a relativa ao aspecto normativo da Análise Econômica do Direito. Explicar, por meio de uma análise econômica, a ocorrência de um determinado fenômeno jurídico é diferente de fazer uma proposição normativa com bases crematísticas (no caso, utilitárias maximização da utilidade). No momento em que a Escola da Análise Econômica do Direito, assumindo o seu caráter normativo, tece qualquer proposição nesse sentido - por exemplo, no sentido de buscar maior produtividade, ou produção, por meio da criação ou da extinção de um determinado instituto jurídico - está se referindo à uma dimensão crematística encerrada no Direito.

Até aí, isso está de acordo com a teoria econômica de Aristóteles: esta não limita, de forma alguma, a crematística à obtenção de bens exclusivamente para o limite mínimo de subsistência; ao contrário, o bem viver inclui seus luxos, e é, sem dúvida, uma falácia afirmar que porque um estado em particular - o mero viver, tomado por riquezas supérfluas, e a vida em função delas - é ruim, o seu oposto completo seria bom. Não: o "justo meio", na teoria econômica de Aristóteles, encontra-se na negação das superficialidades à medida em que ameaçarem a integridade do todo. Nesse sentido, coloca J. S. MACKENZIE ${ }^{48}$

[Tradução livre] "Ter necessidades é ter esperanças, e ter esperanças é estar no caminho para o progresso. É verdade que alguns dos movimentos mais característicos dos tempos recentes (...) incluíram como elemento essencial uma simplificação de nosso modo de vida e um esforço no sentido de voltar às condições naturais; e eu estou muito longe de levantar qualquer dúvida sobre a sabedoria dessas empreitadas. Mas, se tais esforços envolveriam uma restrição de nossas demandas em alguns aspectos, eles implicariam uma

\footnotetext{
${ }^{48}$ MACKENZIE, J. S.. The relation between ethics and economics. Pg 297. Original: "To have wants is to have hopes, and to have hopes is to be in the way of progress. It is true that some of the most characteristic movements of recent times (...) involve as one essential element a simplification of our modes of life and an effort to get back to more natural conditions; and I am very far from wishing to throw any doubt on the wisdom of such endeavors. But if those efforts would involve a restriction of our wants in some respects, they would imply an extension of them in others. What is desired is not to suppress wants, but to direct them wisely".
} 
Ou seja, o problema não é a produção em si, ou o fato de alguns bens serem supérfluos, e sim o que se deve fazer, e em que direção deve atuar 0 sistema produtivo como um todo. A aquisição de riquezas não é um mal, o mal é consideração disto como sendo um fim último, o fim supremo a ser buscado, seja pela sociedade, seja pelo homem individualmente considerado, numa intersecção entre Ética, Política e Direito, que caracteriza a obra de Aristóteles.

Para Aristóteles, o nível de capacidade produtiva de uma sociedade é assunto que interessa tanto à economia quanto à crematística; porém, é suficiente para esta, e não para aquela. Para a economia, mais importa o direcionamento que se dá a essa capacidade de produção, e não a sua magnitude em termos puramente quantitativos. Assim, a Análise Econômica do Direito se manifesta como estando de acordo com a teoria econômica aristotélica - desde que se ressalte o fato de que a dimensão crematística é só parte do fenômeno econômico: as proposições normativas da Escola da Análise Econômica do Direito fazem parte da crematística, e não da economia, em Aristóteles.

Nesse sentido, a sua limitação em relação ao Direito é clara: a crematística é uma dimensão da economia, a qual está subordinada à política; e o Direito, por sua vez, como ciência prática, se sujeita aos mandamentos da ética e da política. Logo, a Análise Econômica do Direito, dentro dessa perspectiva, pode apenas explicar uma parte do Direito: sua análise descritiva e suas proposições normativas serão sempre, assim, limitadas, ainda que corretas e acertadas. 


\section{BIBLIOGRAFIA}

ARISTÓTELES. Política. São Paulo: Martin Claret, 2004.

ARISTÓTELES, Ética a nicômaco. São Paulo: Martin Claret, 2004.

COASE, Ronald. The nature of the firm. Oxford, U.K.: Blackwell Publishing. Economica, New Series, Vol. 4, No. 16, Nov. 1937, pp. 386-405.

COELHO, José Fernando. Contratos agrários: uma visão neo-agrarista. Curitiba: Juruá, 2006.

MACKENZIE, J. S. The relation between ethics and economics. International Journal of Ethics, Vol. 3, No. 3 (Abril, 1893). Chicago: The University of Chicago Press pg. 281-308.

POSNER, Richard. Economic analysis of law. $6^{\text {a }}$ ed. New York, NY, USA: Aspen Publisher's, 2002.

POSNER, Richard. The law and economics of contractual interpretation, In Texas Law Review, Vol. 83, N. 06, 2005. Pg. 1583.

RODRIGUES, Vasco. Análise económica do direito: uma introdução. Coimbra, Portugal: Livraria Almedina. 1를. 2007.

SCHUMACHER, E. F. O negócio é ser pequeno. São Paulo: Círculo do Livro, 1973

WILLIAMSON, Oliver. The economic institutions of capitalism. $1^{\text {a }}$ ed. New York, NY, USA: The Free Press, 1985. 